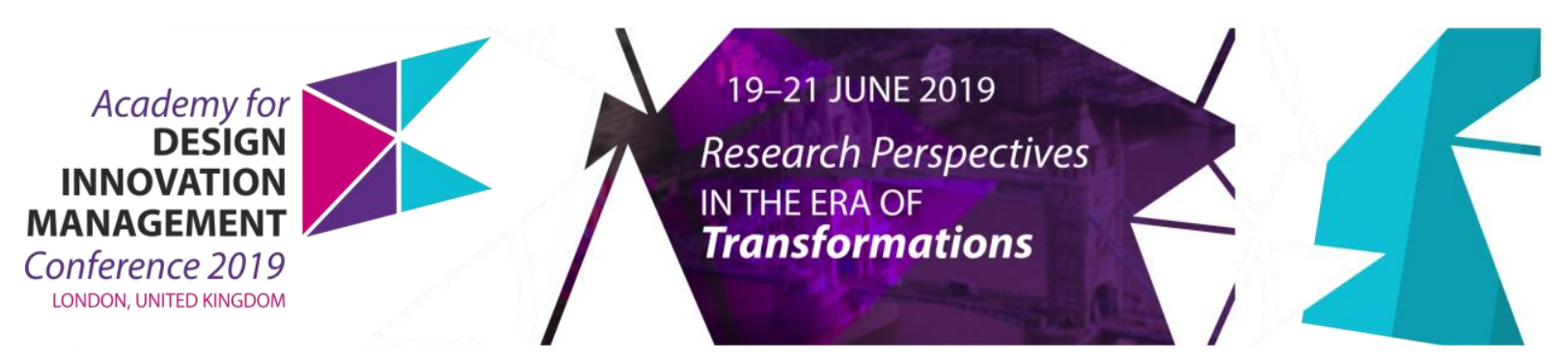

\title{
Towards the exploration of Gender awareness in Human- centred design
}

\author{
KHAYAMIAN ESFAHANI Bahar*; MORRIS Richard and ERICKSON Mark \\ University of Brighton, United Kingdom \\ * corresponding author e-mail: Bke10@Brighton.ac.uk \\ doi: 10.33114/adim.2019.02.416
}

\begin{abstract}
The primary aim of the human-centred design (HCD) approach is to identify the user needs. However, we argue that there is a lack of understanding of, and even awareness of, gender in HCD. This approach sees gender as static and stable regarding male or female such that the implication of principles in products, systems or services appeals to one gender or another linking gender differences, and stereotypes. To illustrate this, the investigation was conducted in the context of fostering sun protection behaviour in young men. Participatory design sessions were deployed to investigate the role of gender in the HCD and how it can be used to foster sun protection behaviour. We have concluded with the development of a novel gender aware HCD approach which opens avenues for design research and practice for increasing emphasis on the influence of the designer's own gender and their gendered perceptions in their designs.
\end{abstract}

Keywords: Human-centred design, gender, participatory design, sun protection, young men

\section{Introduction}

Skin cancer caused by exposure to sunlight and sunburn is the second biggest killer of young men and the most preventable cancer (Cancer Research UK, 2014). Young men, age 18 to 24 are at higher risk of developing skin cancer due to the low levels of sun protection behaviour. This is despite the growth in the market for the health promotion products produced by the cosmetics and sunscreen industries aimed to raise awareness about the risks associated with sun exposure and sunburn. This paper presents the development of strategies to foster sun protection behaviour in young men by designing new human-centred interventions.

Human-Centred design (HCD) has been applied in numerous disciplines including engineering, social platforms, business and industry, and healthcare. The HCD approach guides designers to understand human interaction on a daily basis through the psychology of human actions that impose its narrative on the field of design of objects. The primary aim of the HCD approach is aimed at understanding the users' needs and how to influence their behaviour. HCD is focused to improve the communication process and interaction between the products and the user through understanding the meanings attached while interacting with an object, and this could be improved by focusing on how the user interprets the product in terms of their gender. The lack of understanding of, and even awareness of, gender in the HCD principles were identified. So far, very little attention has been paid to the role of gender in the design of products (Moss, 2009). The aim of this paper is to explore the role of gender in the human-centred design and how it can be used to foster sun protection behaviour.

The paper proceeds as follows: Section 2 is concerned with the literature that surrounds the HCD. Also, it reviews the importance of gender and masculinity and its role in young men health-related behaviours. Further, this

This work is licensed under a Creative Commons Attribution-NonCommercialShare Alike 4.0 International License. https://creativecommons.org/licenses/by-nc-sa/4.0/ 
section reviews the HCD approach to achieve the desired health-related behaviour. Section 3 discusses the deployed method to investigate the role of gender in HCD. Section 4 draws together the key findings emerged through participatory design sessions. Lastly, it opens suggestions for design implications and future research in the field of gender and design.

\section{Literature review}

\section{Human-Centred Design}

HCD is a creative approach to problem-solving that prioritises understanding human needs. HCD is based on the key principles of human psychology in order to develop products, services, and systems that are understandable, usable and desirable for people (Norman, 2013). Norman describes the interaction between the user and a physical object through the HCD principles such as 'affordances' and 'signifiers' (Norman, 2013, p.45). Norman defined affordances and signifiers based on the interpretation of how an object is perceivable to define the possible actions for interacting with an object based on the physical characteristics of objects such as size, shape, and colour which act as signifiers to show how users can interact with the objects. He also clarified the concept of affordances and signifiers as perceivable cues related to our interpretation and our past knowledge and experiences applied to our perception.

Objects targeted specifically at male or female audience, highlight differences based on gender stereotypes targeted at men and women (Karin et al., 2012, p.88). For example, products targeted at the female audience are using aesthetic characteristics such as soft, clean, organic shapes, and bright colours (Moss, 2009). We can see this when we look at, for example, Gillette razors targeted at the male or female audience; the way these differ in terms of shape, colour and material indicate the deployment of pre-existing stereotypes regarding gender and gendered norms. In this context, affordances and signifiers can be influenced by gendered based clues according to the designers' own preconceptions and pre-identified gender stereotypes.

While HCD accounts of design principles is based on a social psychology approach that explores human needs, this approach is based on a broad understanding of the shared values and common actions of all people as men or women but is not aware of the concept of gender as performative and relational. The HCD approach sees gender as static and stable relating male and female stereotypes to one gender or another. However, gender is performed and is multiple, dynamic, fluid and relational and is constructed in various ways over time in a particular context. But HCD links gender differences, gender inequalities and stereotypes to the products, services and brands. This contributes to the design products that are influenced by the designer's own stereotypical norms such as 'blue for boys' and 'pink for girls. In contrast, we can see that gender is socially constructed over time and understanding young men experience requires us to move beyond traditional, stereotypical and pre-identified gendered characteristics.

\section{Gender}

The concept of gender has been challenged and widely used as a social constructionism. Harriet Bradley, who is a sociologist and a major contributor in the field of gender studies refers to the sociological concept of gender as a lived experience and the nature of gender relations. Bradley, discusses that gender is socially constructed in contrast to the biological determinations and provides an explanation for the social patterns by men and women in society. The implication of this is that gender is based on the social understanding of people in relation to their gendered social groups (Bradley, 2013). More broadly, to understand gender we need to determine what is meant by sex and in particular sexuality. The concept of sex is biologically determined and fixed at birth. Sex explains the biological sexual orientation of a person and classifies people based on their natural biological characteristics as male or female. However, expressing sexuality is embedded in our cultures that are in relation to the person's sexual orientation and the way people represent their gender that reflects different characteristics associated with gender roles that form masculinity and femininity. According to Bradley (2013), gender is described as the cultural definitions of masculinity or femininity and the power between men and women that are not stable and fixed, but it develops over time in interaction with cultural and social values (Bradley, 2013, p.3).

According to Bradley, gender is persistent, everything from TV programs to car designs is gendered artefacts, and society and the world are gendered. Gender is described as the cultural definitions of masculinity or femininity and the power between men and women that are not stable and fixed, but it develops over time in interaction with cultural and social values (Bradley, 2013, p.3). Masculinity is the core theme of understanding 
young men, defined by Connell as men's endorsement of traditional attitudes and behaviour that is socially constructed (Connell, 1987). In order to understand the concept of masculinity, we need to move on to the core concept of gender.

As a result, masculinity and femininity are constructed around specific cultural and social norms linked with gender inequalities in the society. This shows the connection between sex, gender and sexuality associated with authority, power and gender inequalities and the discourses of masculinity and femininity. Therefore, the root of masculinity and femininity is formed through the gender differences associated with the social and cultural impacts in the society related to being a male or female (Bradley, 2013, p.4). In line with the debates concerning gender by Harriet Bradley, Frosh et al. discuss the construction of gender not from the biological sense or genetically formed but as set of performative acts or actively 'doing gender' with a relational nature. Gender is culturally formed in accordance with the norms of society produced over time through our behaviours performing being a man or women. Frosh et al. describe masculinity as a dynamic process of gender or actively performing gender influenced majorly from a leading gender theorist; Judith Butler (Frosh et al.,2002, p.11). Frosh et al. acknowledge that there are multiple modes of masculinity or approved modes of 'being men' constructed by men that are socially constructed and fluid in dynamic ways and open to reconstruction in different contexts (Frosh et al.,2002, p.12). As Frosh et al. (2002, p.55) note: "masculinities are made into, and lived as, natural or essential identities". Overall, masculinity is a performative act; gender is a performance, and it changes in relation to our interactions and the environment. However, the HCD fundamental model of human action is based on a broad understanding of the shared values and common actions of all people.

Norman holds the view that despite the given variations and experience that affects individuals, fundamentally people approach the world in the same way regarding their perceptions, activities and the way they approach objects. Based on this model, human behaviour can be predictable on many occasions. However, gender is not simply external to us, but are built up and constituted over time and through interactions. This can be seen particularly in the dynamic patterns of our behaviour over time. This means that new designs transform over time in relation to particular contexts. Having identified this gap in the literature, this paper brings together the HCD approach and understanding gender performances to address the poor sun protection behaviour in young men. HCD provides guidance to explore the elements that fulfil the needs of young men through understanding the underlying meanings people attach while interacting with objects. For this purpose, the methodological approach taken in this research is an interpretive methodology to explore the underlying meaning people attach while interacting with object related to their gender.

\section{Methods}

\section{Participatory design sessions}

Participatory design sessions were deployed mainly focused on the act of participation, where the user was involved in all the stages of the HCD process and went beyond the traditional concepts of 'design for users' to 'design with users'. This study was conducted through eight participatory design sessions. A total of eight groups with four to six participants took part in this study for 120 minutes. In total, 23 male participants and seven female participants participated, and each session followed the same structure.

The main criteria for selecting the participants is in relation to the demographic factors including their age and gender. Since the nature of the methods including participatory design requires small groups of participants for the more focused and in-depth result, each session of the study involves direct user involvement with four to six participants. The participants were divided into two main categories including the users who are experts in the context and the subject expert demonstrated below.

The Participants will be recruited from the University of Brighton for a selection of young men and women age 18 to 24. Criteria for selecting the groups are as follows:

- User experts: male only group: male participants age between 18 and 24

- User experts: male and female in mixed-gender group: male and female participants age 18 and 24

- Subject experts: male and female experts from the fields of design, gender studies

The first stage of the study explored the participants' interpretation of products language, including the colours, shape and form. The interaction between the participants and the objects provides an opportunity to get participants thinking about product language, gender and how they interact and communicate with 
objects. Also, this stage explores product language towards non-gender specific language in relation to the interpretation of the physical aspects of the products such as colours, material and shape as well as the internal meanings embedded in their interactions. In the review of the literature, the latest products targeting non-gender specific are evoked in a gender-specific language. Although, the market's shift towards gender diversity and gender-neutral products are growing in the lead brand companies such as Apple. However, the language embedded in these products are still gendered specific.

The second stage of the study was the design phase where the participants themselves designed sun protection interventions. This stage empowered the participants as designers, helping them to express their creativity, while aspects of their interactions were observed in relation to their gender. This led to innovative interventions for improving the low levels of sun protection use in young men. The co-design technique involves the user in the design process to meet their needs from their perception when the user is in full control and empowered in the sessions (Holtzblatt et al., 2005). In this technique, participants are actively involved and exposes the deep experience of participants in relation to the context through the illustration of their tacit knowledge including the hidden needs that are not fully known to the user. Tacit knowledge is subconscious, personal and known to the user but cannot be expressed explicitly in words as it is linked to skills and experiences, "knowledge that people can act upon, but cannot readily express in words." (Visser, 2009, p.4). On this basis, the user experts and the subject experts were able to communicate their tacit knowledge through the visual articulation of their ideas and needs in their designs. All the conducted sessions took place in the Creativity Centre at the University of Brighton and involved male-only groups, mixed-gender groups and an expert group. The purpose of this was to highlight the differences in group dynamics, specifically the participants' behaviour, and the enactment of their gender in relation to these different groups. The different dynamics of male-only interviews, as opposed to mixed-gender interviews, provide an opportunity to look at the group dynamics in both categories and see how this was linked with the participants' enactment of gender and masculinity.

\section{The procedure}

\section{Phase 1: product language}

Initially, the participants were introduced to a number of products, as presented in the following subsections. This phase of the study aimed to explore gender values embedded in the design of products and the ways in which they were perceived by both male and (when present in other sessions) female participants.

The investigation involved the exploration of product language in terms of 1) products targeted at both male and female genders, and 2) gender-specific products and advertisements. This phase of the study aimed to explore the interaction between the products and the participants, and the language and meanings the participants perceived. Initially, the illustrated products below (Figure 1) targeting both male and female target audience advertised as gender-neutral were presented to the participants.

The participants sat around a table while images of the product examples were presented to them. The researcher asked participants to share their opinions about the products, their motives for using the products. For the next stage of the study, a range of products (Figure 2) targeted only at the male or female audience was outlined to the participants.
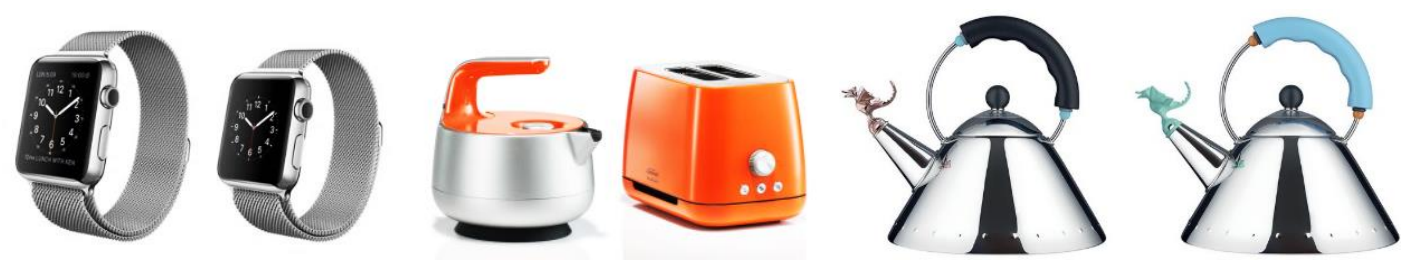

Figure 1: Apple watch and Kettle and toaster by Marc Newson, Alessi's hob kettle by Michael Groves (the product photos are printed with all rights reserved) 

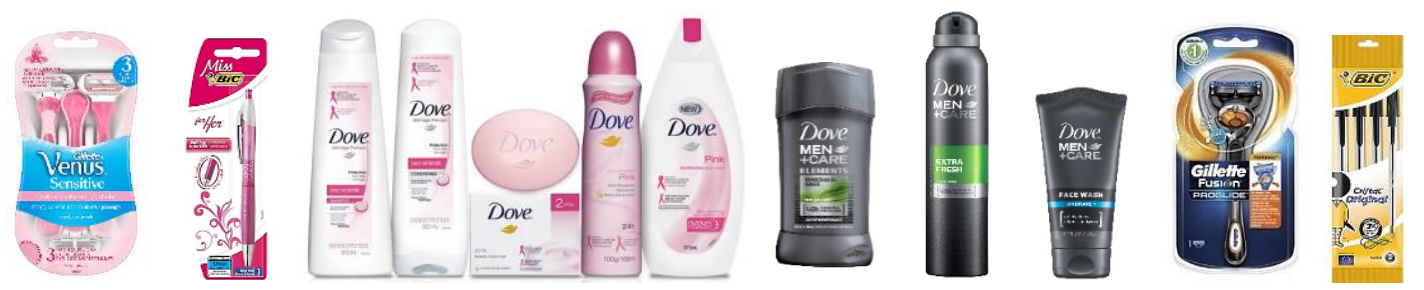

Figure 2: Gillette razor and Bic Pen. The Dove products targeted towards women are on the left and products targeted towards men are on the right (the product photos are printed with all rights reserved)

As illustrated above, the most successful leading brands have embedded masculine or feminine attributes in their advertisements. Advertisements portray patterns that feature specific gender subjects. This includes popular gender representations focused on displaying gender differences between males and females based on stereotypes (Goffman, 1987).

The next stage of the study was an investigation of gender patterns portrayed in product advertisements aimed towards specific genders. This was the final stage of the product language phase and focused on the participants' perception of the advertisements shown in the following section. The researcher is focused on the participants' interactions and attitudes in relation to advertisements featuring human subjects linked with their own gender and masculinity. Various leading brands have embedded masculine or feminine attributes in their advertisements, with gender-specific advertisements portraying popular gender representations focused on the differences between males and females, based on stereotypes. The Dove Men+Care cosmetics advertisements featuring male subjects were discussed. As illustrated in Figure 2, the Dove brand is designed with a specific name (Dove Men+Care) and features grey coloured bottles with a bold font. This brand is very popular and successful, and its advertising campaigns are centred on using 'real' people, rather than professional models. The Dove 'Men+Care' advertisements depict ways of being a real man and promote an image of real men with real strength (Dove, 2018). This is linked to the concept of masculinity, as it portrays popular concepts associated with being a man (Frosh et al., 2002,p.17).

\section{Key themes}

The following section overviews the key themes emerged from an in-depth interpretation of the gathered data from phase one: product language. Initially, the collected data were transcribed and coded using thematic analysis in order to gain insights into identifying and analysing patterns and themes from the perspectives of the participants (Braun \& Clarke, 2006).

All the conducted sessions produced a range of qualitative data including images, audio, video recordings, observation notes as texts. The collected data is discussed and analysed using an inductive approach as the data emerge new themes through the comparison of collected data in the mixed, male-only an expert group. The key findings from the analysed data suggest the expression of gender and the dominant discourses of masculinity (Connell, 2005) in commonly reoccurring patterns and themes collated are developed in connection with identifying the meanings, motivations, and experiences of the participants.

These themes portray the ways the participants seem to be concerned with 'being' like others, young men don't want to be seen as different(Mac an Ghaill, 1994). Their responses came across as their fear of being seen different as it seems they want to be accepted by being like others. The results outlined the participants' gender identity influences their perception and understanding of the appearance of products including affordances and signifiers.

\section{Theme 1: Gendered responses and meanings}

Almost all participants in the main study expressed their interest in the products which were targeted towards their own gender. In particular, they identified the main characteristics of products such as colours, shapes and materials associated with specific gender and products as targeted for either male with masculine characteristics or female with feminine characteristics. However, they recognized a range of features and meanings attached to the products as 'naturalized'. For them, these features of products are an important consideration when buying and using them targeted towards a particular gender. Many male participants feel this way and they recognised the gendered features of the products aligned with the construction of their masculinity. As the following participants explained: 
[JS, M, 21]: Male colours are dark blue and black, female products are curvy, and I usually buy the products that are dark colours and are for men, the font and packaging of products for men are with straight lines or as a square.

[EA, $M, 20]$ : I buy products that are dark colours and are for men, if a product is designed for women, it will have bright colours and will be soft and smells girly such as Nivea creams, flowery smells are for girls

[SH, M, 24]: I always buy Gillette shaving cream that is specifically designed for men, in general, products that are designed for men look more reliable as it's guaranteed that it will do the job.

[EH, M, 19,]: all the men's products are dark coloured like black and blue and women are more pink and white, if a product is for men then it's for him.

Almost all the participants recognised products targeted at their gender through stereotypical colours such as 'pink for girls' and 'blue for boys'. This seems to be something they expect and an important consideration when they use a product. Almost all male participants avoid using products that are not designed for their gender. In some cases, this attitude was expressed repeatedly by the younger male participants aged 21 and under.

\section{Theme 2: Masculinity}

The primary motivation in choosing products by the male participants shows a link with products targeted at their gender. Here are a few examples of the way they described their unwillingness in using products that are not designed towards their gender:

[JS, M, 21]: I would never use female shampoos because they are smelling different to male products and I don't want to walk passing someone who thinks 'he smells like a girl'

[EA, M, 20]: there shouldn't be any difference between male and female products because if it's the same product but I always buy men's products because it's important to me.

[JP, M, 20,]: James said he won't use female products because it's very different like Lynx for men and lynx for women, they are completely different and the difference is massive.

[KE, M, 21]: I won't buy the pink pen because it says Bic for her and its pink, I rather blue or transparent.

[SM, M, 20]: there is no way I wear a feminine watch, also I don't like flowery patterns products like the blender, it's cool but I won't buy it, but I will buy it for my girlfriend.

[JP, M, 20]: Men buy first thing it comes across to them when they want to buy something such as shampoos and they prefer something that does everything and it's less detailed and it says that it's for men so it's what they want, if it says for men so it's designed for men. The female products are very different like Lynx for men and lynx for women, they are completely different and the difference is massive, most people will think you are weird for using a female product

The demonstrated comments refer back to the fragility of masculinity and it needs for protection (Frosh et al., 2002). However, a few male participants indicated more flexibility in using products that are not targeted towards their gender. As they explained:

[AD, M, 22]: I don't mind the flavour of shower gels and I usually buy the cheapest product. For example, I won't necessarily choose the boy's shaving cream as it doesn't bother me if it's marketed towards girls or products with flowery patterns.

[SH, M, 24]: I don't mind wearing thin watches because it's cool, in fact, I'm wearing one now that is with thin straps and rounded screen. I think it looks friendlier as Stephen's watch looks rigid, not friendly, not welcoming, over the size, over the top and Hefty. I would buy pink tools if it works better as I have worked in the construction sites before and you can see the tools better because of the contrast.

[AL, M, 21]: If there is no other pen in a shop I will buy the pink one.

These participants explained their motivations and reasons behind their choice of objects and their openness to use products not designed specifically for their gender. 
The variations in attitudes and behaviour of the male participants in comparison with the female participants indicate their gender differences created and reacted in their responses associated with displaying patterns of masculine or feminine attitude and behaviour. This is relevant in developing of understanding of the male participants' attitude and behaviour in relation to their gender characteristics and masculinity embedded in their motivations. At this point, we should note that almost all male participants expressed views and ideas associated with different versions of hegemonic masculinity. Given their social class and age, this is not surprising (Connell, 2005).

This analysis also indicated that understanding of the ways in which the male participants express their masculinity is in relation with their age as the male respondents seem concerned about their masculinity as came across as defensive and it needs the protection of the male participants' masculinity through choosing particular products.

\section{Theme 3: Same-sex body contact}

All the male participants indicated that their main worry for sun protection and applying sunscreens is regarding the application of sunscreen on their body. It is understandable from the ways they present themselves towards stereotypical gender boundaries related to the ways heteronormativity shapes their perceptions (Connell, 2005). This indicates the understanding of masculinities related to the participants fear of seen as homosexual and expression of heteronormativity through expressing their avoidance of same-sex body contact.

As they said:

[RM, M, 21]: I would never ask a guy to put sunscreen on my back. It is not a guy thing to do.

[JP, M, 20]: I won't put sunscreens on his back and won't ask friends.

[SM, M, 20]: if I go to the beach as just guys they won't put sunscreens on each other's back because it's sexual,

Then Stephen said 'so you think it's awkward' and then Sam said 'I didn't say it's awkward'.

[EM, M, 22]: I won't put sunscreen on guy friends back because people around us will judge and guys back is hairy.

[AH, M, 21]: if I go on a family holiday I will use the sunscreen but when I'm with my friends and there is something awkward about using sunscreens, I am not worried about what suntan to buy but how to apply it and avoid body contact with your friends' back, something that sprays sunscreens everywhere would be good

[RM, M, 21]: I would never ask a guy to put sunscreen on my back

In response to these comments, almost all the male participants in the group agreed with their comments. However, a few of them indicated more flexibility with body tactile as outlined below:

[SH, M, 24]: you just say I just need to get through this awkward moment and you apply the sunscreen on someone's back.

[JB, M, 23]: My girlfriend put sunscreen on my back and because I've got tattoos on my back I don't mind anyone else put sunscreens on my back.

Although it is apparent that they still need to justify themselves and in need to protect their gender boundaries and masculinity, they show more openness and flexibility. Overall, Table 1 provides the number of participants who are in need. 
Table 1: Attitudes toward same-sex body contact

\begin{tabular}{|l|c|c|c|}
\hline $\begin{array}{c}\text { Positive and negative } \\
\text { attitude to same-sex body } \\
\text { contact }\end{array}$ & $\begin{array}{c}\text { Male Participants } \\
N=21\end{array}$ & $\begin{array}{c}\text { Female Participants } \\
N=6\end{array}$ & $\begin{array}{c}\text { All Experts participants } \\
N=3\end{array}$ \\
\hline $\begin{array}{l}\text { Positive attitude to } \\
\text { same-sex body contact }\end{array}$ & 20 & 0 & $2 \mathrm{M}$ \\
\hline $\begin{array}{l}\text { Negative attitude to } \\
\text { same-sex body contact }\end{array}$ & 1 & 6 & $1 \mathrm{~F}$ \\
\hline
\end{tabular}

In this case, in terms of ways in which they are in need to assert popular ways of being a man such as being heterosexual is important in the construction of their masculinity (Connell \& Messerschmidt, 2005). From this analysis, fear of being seen as homosexual is one of the main reasons for the way young males present themselves towards the stereotypical ways of being like other men.

In addition, the participants also indicated various forms of asserting their masculinity such as playing rugby. Playing sports such as rugby is very popular among men and very significant in ways men construct their gendered identity and masculinity (Murray et al., 2016).

\section{Phase 2: Design}

The final phase of this study was the design phase, which was facilitated through various co-design techniques, such as ideation and brainstorming (Simonsen \& Robertson, 2013). Ideation and brainstorming activities engage the participants to articulate their creativity and innovative ideas while empowering them as designers. The participants were guided through the practical activity of ideation to generate new sun protection interventions. During this stage, the participants were encouraged to ideate sun protection interventions to improve young men's sun protection behaviour. This involved them reflecting on the information from the session and applying it to new and innovative interventions.Overall the design outcomes were a range of sun protection interventions including the following categories based on the researcher's inferences: 1) Sunscreen bottles 2) Sunscreen applicators and 3) Wearable technology. The outcomes designed by each group and the participants from the discussed categories are mapped in Table 2.

Table 02: Overall design outcomes produced by each group, the number of each participant is presented numerically and indicated by their gender, Female (F) Male (M)

\begin{tabular}{|l|c|c|c|c|}
\hline \multicolumn{1}{|c|}{ Main study groups } & $\begin{array}{c}\text { Participants } \\
\text { male and female) }\end{array}$ & $\begin{array}{c}\text { Sunscreen Bottles } \\
\text { Sunscreen } \\
\text { applicators }\end{array}$ & Wearable technology \\
\hline Group 1 & $4 \mathrm{M}$ & $1 \mathrm{M}$ & $2 \mathrm{M}$ & $1 \mathrm{M}$ \\
\hline Group 2 & $3 \mathrm{M}, 1 \mathrm{~F}$ & $2 \mathrm{M}, 1 \mathrm{~F}$ & & $3 \mathrm{M}$ \\
\hline Group 3 & $3 \mathrm{M}, 1 \mathrm{~F}$ & $1 \mathrm{~F}$ & & $2 \mathrm{M}$ \\
\hline Group 4 & $3 \mathrm{M}, 2 \mathrm{~F}$ & $1 \mathrm{M}, 2 \mathrm{~F}$ & $2 \mathrm{~F}$ & \\
\hline Group 5 & $2 \mathrm{M}, 2 \mathrm{~F}$ & & & $1 \mathrm{M}$ \\
\hline Group 6 & $4 \mathrm{M}$ & $4 \mathrm{M}$ & & $1 \mathrm{M}$ \\
\hline Group 7 & $4 \mathrm{M}$ & $3 \mathrm{M}$ & & \\
\hline Group 8 & $2 \mathrm{M}, 1 \mathrm{~F}$ & & & \\
\hline
\end{tabular}

As discussed in Section 2, affordances and signifiers are fundamentally important in understanding how an object can be used by a particular actor and is the key principle of good design (Norman, 2013). Norman defined affordances and signifiers based on the interpretation of how an object is perceivable to define the possible actions for interacting with an object. He also clarified the concept of affordances and signifiers as perceivable cues related to our interpretation and our past knowledge and experiences applied to our perception. Giacomin added the usefulness of affordances and signifiers related to the importance of 
understanding the way people interact with physical objects (Giacomin, 2014). He indicated that the implication of HCD principles through a wide range of affordances in a product, system or service results in good interaction design that brings out commercial and business success.

The discussed elements pinpoint the participants' own gender reflections embedded in the design outcomes. Also, their reflections have influenced the design of the affordances and signifiers. This analysis is pushed further through a consideration of the male participants' accounts of their gender and masculinity expressed in their designs. A potential association is expected between the male participants and their designs, validating their gender and protecting their masculinity. The analysis of the design outcomes outlines a range of characteristics in the participants' design related to stereotypes, expression of gender and hegemonic masculinity. A few examples of the design outcomes are illustrated in below (Figure 3). As illustrated below, the male participants expressed their interests towards designs inked with their heteronormativity such as the sunscreen applicator in the form of a roller ball. The male participants in the expert group were also concerned with the application of sunscreen on their body and avoiding same-sex body contact. Avoiding same-sex body contact was often presented as something which usually the male participants are concerned in these outcomes. This provides evidence in the discussed material that the preferences applied in the design of affordances and signifiers towards the protection of their masculinity.

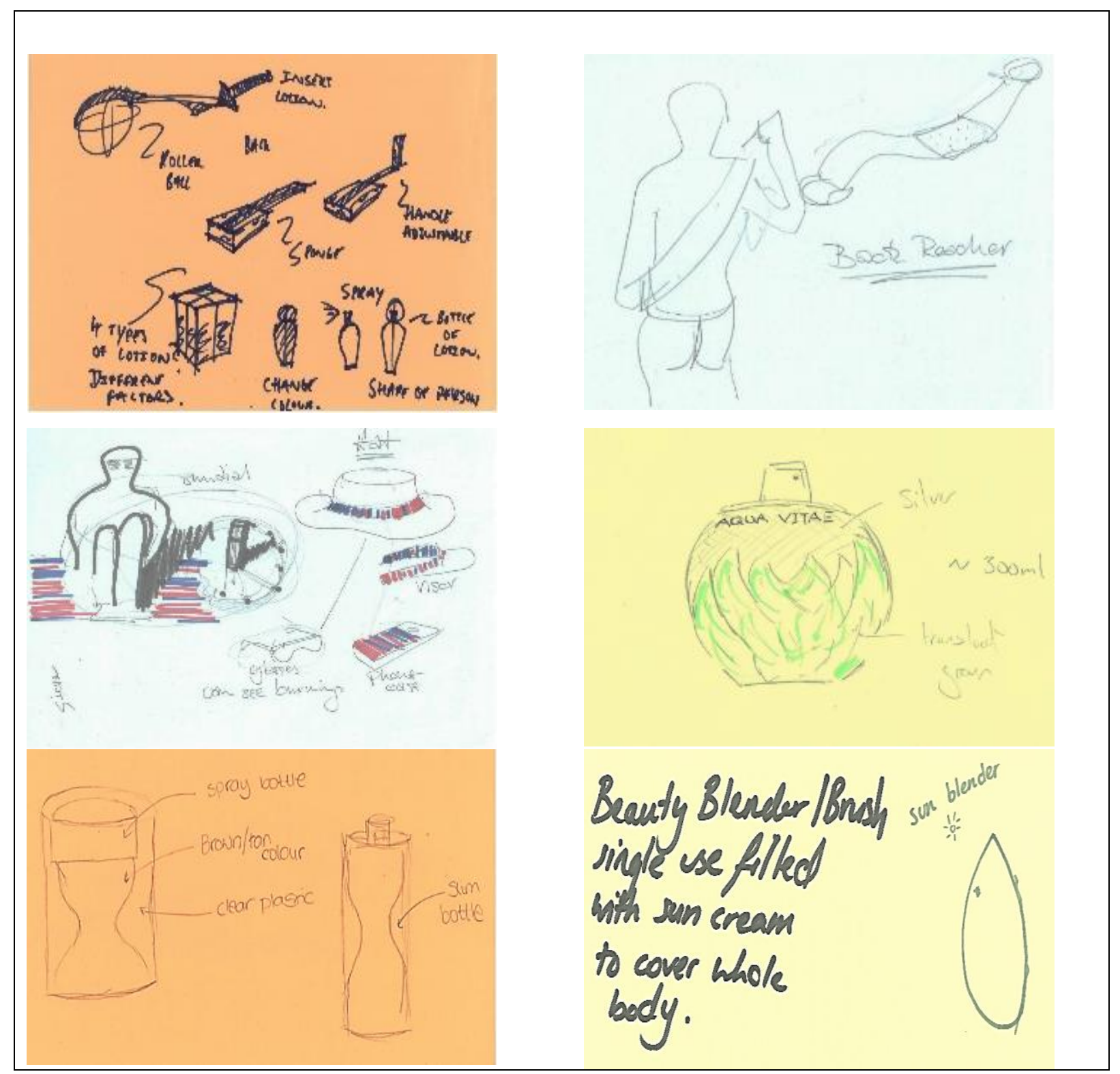

Figure 3: Examples of the design outcomes by 4 male participants on the top and 2 female participants on the bottom 
The design outcomes indicated a link in the outcomes designed by the male or female participants and the reflection of their own gendered characteristics. Amongst the discussed aspects of the HCD principles, we draw out the role of gender embedded in the design of affordances and signifiers and how these elements are influenced in each design outcome. The results highlighted links with the influence of gendered characteristics in each design in relation to masculine and feminine attributes.

It is clear from the participants' comments that their behavioural patterns are asserted in relation to their challenges of being the same as others and to conform to their gender roles. As it was shown both male and female participants portrayed their perception of masculine and feminine attributes in the design of affordances and signifiers. A possible explanation for these differences is related to the participants' general preference amongst their design with an inclination towards their own gender. This goes beyond deconstructing affordances and signifiers influenced by gender roles and developed through a range of features such as lines, material, shapes, typography, colours, labels and use of details. The continues patterns of the participants' behaviour towards conforming to preconceived ideas and stereotypes is related to the ways the individuals try to conform to the normative gender roles and need various ways of showing their masculinity as the society has become more individuated.

\section{Conclusion}

The results outlined the participants' gender identity influences their perception and understanding of the appearance of products including affordances and signifiers. The reoccurring emphasis on the perceived characteristics of products targeted at the male audience showed a clear preference of male participants towards maintaining their masculine identity. Their preferences towards the appearance of popular maletargeted cosmetic products such as DOVE MEN+CARE and NIVEA MEN was an additional influence on the overall appearance of design outcomes. In addition, further explanations of their preferences were related to the product properties including chunky shapes, dark colours such as navy blue, grey and black, the appearance of silver chrome material. This suggests the deployment of their gendered tropes to understand these objects and have a gendered view of products.

In this context, affordances and signifiers guide the user to understand how to interact with an object based on the designers' gendered perceptions associated with traditionally male or female gender roles. The purpose of a gender-aware HCD is to add awareness for the influence of designers' gender perceptions in the HCD process before they are applied in the characteristic of products through affordances and signifiers. The designers' perceptions have a direct impact on how affordances and signifiers are designed and interpreted by the user which can contradict their gender identity. Male participants' perceptions of products were clearly influenced by their gender. This clearly links with the ways the HCD characteristics including affordances and signifiers were influenced by the participants' own gender. The participants' gender and masculine attributes were linked with the gendered characteristics applied in various features of the design outcomes. We saw the interplay of gender in the way affordances and signifiers were designed in these products.

This analysis guides design research towards understanding the way that gender, being a male or female designer, affects the designer's perceptions. This can suggest the way designers' gender identity play a key role in influencing affordances and signifiers which emerge in a range of physical features of a design such as lines, material, shapes, colours, and labels. The implication of adding gender awareness in the HCD approach for designers can result in addressing the gap between the world of designers and users. Bridging this gap requires designers to go beyond their gender perceptions and focus on the users' gender identities. Making the role of gender visible in designers' perceptions broadens the design of affordances and signifiers beyond the stereotypical perceptions of gender.

In addition, to foster sun protection behaviour in young men it is important to consider how gender is implied in affordances and signifiers of the sun protection products. We can facilitate this by combining HCD principles and practices with an increased and reflexive gender awareness. Doing this produces design outcomes for sun protection that are more appropriate to young men. Taking this kind of approach will move designers to consider affordances and signifiers in new and innovative ways, and this will have considerable implications in areas beyond sun protection design. The implication of GAHCD approach for designers can result in addressing the gap between the world of designers and users. Bridging this gap requires designers to go beyond their gender perceptions and focus on the users' gender identities. Making the role of gender visible in designers' perceptions broadens the design of affordances and signifiers beyond the stereotypical perceptions of gender. 


\section{Future work}

This paper has opened new avenues for future research in the following direction: considering the role of a gender-aware HCD approach for the wider design community. This means to consider the implications of employing gender aware HCD in the wider design community. This would include academic design research, design education focused on HCD (product design and industrial design), and design agencies. This could include design research and practice to increase the emphasis on the importance of gender, helping to support and encourage gender-awareness in the HCD process to address user needs in their design solutions. Designers' reflections on the influence of the designer's own gender and their gendered perceptions in their designs is a starting point. This lack of gender-awareness neglects the user's needs to be addressed as it is a crucial element of how the product is established as human-centred. The whole design community should consider moving away from normative gender stereotypes when developing new designs in terms of gender identity of the user to represent fluid and dynamic gender perspectives that are socially constructed in different contexts. Our suggestion is for the Design community to avoid neglecting the designer's gender role influence and move to a closer understanding of user's interpretations of products.

Designers perceptions based on their own pre-conceptions and past experiences produces products based on their perceptions can be in conflict with the user's gender identity. Designers should avoid the influence of their perceptions based on gender stereotypes and enhance understanding of gender, the ways in which the designers can engage in GAHCD to avoid the mistakes of the previous design related to gender bias when designing new products

\section{References}

Bradley, H., 2013. Gender Second Edi., Cambridge: Polity Press.

Braun, V. \& Clarke, V., 2006. Using thematic analysis in psychology. Qualitative Research in Psychology, 3(2), pp.77-101. Available at: http://eprints.uwe.ac.uk/11735 [Accessed July 2, 2016].

Cancer Research UK, 2014. Skin cancer incidence statistics | Cancer Research UK. Available at: http://www.cancerresearchuk.org/health-professional/cancer-statistics/statistics-by-cancer-type/skincancer/incidence [Accessed November 9, 2017].

Connell, R., 1987. Gender and Power. , p.317.

Connell, R., 2005. Masculinities second edi., Cambridge: Polity Press.

Connell, R.W. \& Messerschmidt, J.W., 2005. Hegemonic Masculinity: Rethinking the Concept. Gender \& Society, 19(6), pp.829-859.

Dove Men+Care, 2018. Dove Men's care products. Available at: https://www.dove.com/uk/men-care.html [Accessed August 13, 2018].

Frosh, S., Phoenix, A. \& Pattman, R., 2002. Young masculinities : understanding boys in contemporary society, Palgrave.

Giacomin, J., 2014. What is human centred design? Design Journal, 17(4), pp.606-623.

Goffman, E., 1987. Gender Advertisements, New york: HARPER TORCHBOOK. Available at: http://www.publiccollectors.org/Goffman_Gender.pdf [Accessed September 15, 2017].

Mac an Ghaill, M., 1994. The making of men : masculinities, sexualities and schooling, Open University Press.

Moss, G., 2009. Gender, design and marketing : how gender drives our perception of design and marketing, Gower.

Murray, A. et al., 2016. Constructing Masculinities in the National Rugby League's Footy Show. Sociological Research Online, 21(3), pp.1-14. Available at: http://journals.sagepub.com/doi/10.5153/sro.4044 [Accessed December 10, 2018].

Norman, D.A., 2013. The Design of Everyday Things, Available at:

http://ucdwiki.chuank.com/uploads/Main/UCDReading_wk5.pdf.

Simonsen, J. \& Robertson, T., 2013. Routledge international handbook of participatory design, Routledge. 